Trab. Ling. Aplic., Campinas, 44(2): 247-263, Jul./Dez. 2005

\title{
DILEMAS DA LITERALIDADE NA TRADUÇÃO JURAMENTADA ${ }^{1}$
}

\author{
FRANCIS HENRIK AUBERT \\ (Universidade de São Paulo)
}

\begin{abstract}
RESUMO
A condição "juramentada" da tradução executada por tradutores públicos tende a exigir a adoção de uma postura literalizante, centrada no texto de partida. A natureza dos textos comumente submetidos a esse tipo de tradução tende a exigir uma abordagem comunicativa, substituindo os "modos de dizer" do original pelos "modos de dizer" correntes na comunidade de chegada. Para averiguar de que modo os tradutores públicos lidam com estas demandas conflitantes, analisou-se as tradução de quatro fraseologismos por doze tradutores públicos. Os dados coligidos sugerem uma certa flutuação nas soluções encontradas, a relevância da interlingua como espaço de conciliação das dificuldades tradutórias, bem como uma correlação entre o grau de especificidade (lingüística ou cultural) e o coeficiente de dispersão nas soluções tradutórias propostas.
\end{abstract}

Palavras-chave: tradução juramentada, marcadores culturais, interlingua, fraseologia.

\begin{abstract}
The "sworn" condition of translations produced by public translators will tend to demand a fairly literal approach, focused on the source text. The nature of the texts commonly subjected to this translation mode tends to demand a communicative approach, in which the façons de dire of the original are replaced by the façons de dire current in the target community. In order to verify how public translators deal with these conflicting demands, the translation of four stock phrases by twelve public translators was analyzed. The data obtained suggest a certain fluctuation in the solutions found, the relevance of interlingua as a space in which translation difficulties are reconciled, as well as a correlation between the degree of specificity (whether linguistic or cultural) and the dispersion ratio of the proposed translational solutions.
\end{abstract}

Key-words: sworn translation, cultural markers, interlanguage, phraseology.

\section{O PROBLEMA}

Define-se a tradução juramentada por sua "fé pública". Esta definição pressupõe, no universo de seus praticantes e usuários, uma invariância semântica e discursiva entre o texto da tradução e seu original. Ainda que a lingüística, a análise do discurso, a hermenêutica e as teorizações pós-estruturalistas tenham questionado, por múltiplos ângulos de abordagem, a factibilidade de tal invariância, e, em alguns casos, questionado o próprio

\footnotetext{
${ }^{1}$ Este trabalho representa uma reescrita e uma expansão de algumas reflexões inicialmente publicadas no boletim trimestral da Associação Profissional dos Tradutores Públicos e Intérpretes Comerciais do Estado de São Paulo (ATPIESP) - Ipsis Litteris - em três edições da coluna Dúvidas e Controvérsias. (Aubert, 2004a, 2004b, 2004c).
} 
AUBERT - Dilemas da literalidade na tradução juramentada

conceito de "texto original", resta ser este o pressuposto fundamental para que o texto traduzido seja aceito, na prática de diversos atos jurídicos, como plenamente equivalente ao original, conferindo a este original a validade desejada na comunidade sócio-lingüística de recepção.

Assim caracterizada, a tradução juramentada diferencia-se da grande maioria das demais modalidades de tradução pragmática (isto é, não-literária). Ao contrário do que costumeiramente se define como meta das traduções de cunho informativo, técnico, jornalístico, publicitário, acadêmico, didático, etc., não substitui o texto original, apenas o complementa. Opera, por assim dizer, como uma "transparência" sobre o original. Uma tradução juramentada de um histórico escolar, ou de um instrumento de procuração, não pode ser lida nem aceita, para os diversos fins de tais documentos, independentemente do original; ao contrário, acompanha o original, sendo dele um apêndice e, por sua existência, confere validade ao original. Não se faz de novo original: assume-se como tradução, um pouco como nas edições bilíngües de textos, literários ou outros.

Seria de se esperar que uma tradução com tal propósito adotasse uma postura mais marcadamente tendente à literalidade: formal (morfossintática) e/ou de conteúdo (semântica). Resultaria, assim, em soluções de tradução direta mais do que de tradução oblíqua (Vinay \& Darbelnet, 1958, 1977), em traduções literais, transposições e explicitações mais do que de modulações ou adaptações (Aubert, 1998), semânticas mais do que comunicativas (Newmark, 1981), estrangeirizadoras mais do que domesticadoras (Venuti, 1995, 2002). No entanto, a tipologia e o teor dos textos mais usualmente submetidos à tradução juramentada são de natureza institucional e/ou jurídica (documentos pessoais, históricos escolares e diplomas, procurações, instrumentos contratuais, títulos mobiliários, et simil), tendentes, portanto, a conter marcadores muito específicos da língua/cultura de partida. Essa é uma configuração que, em outros modos de tradução, faz o processo tradutório pender para soluções oblíquas (modulações e adaptações). ${ }^{2}$

Com efeito, estudos anteriores (vide, em especial, Zanotto, 1993) indicam que a tradução de textos jurídicos (na relação tradutória inglês à português) tende a apresentar um índice de modulações e adaptações similares ao da tradução de textos literários $(20,8 \%$, em contraste com $14,7 \%$ na tradução de textos corporativos). Ainda que comportamentos verificados na tradução jurídica não possam ser automaticamente estendidos para a tradução juramentada (pois muitos dos textos submetidos à tradução juramentada não pertencem às diversas subtipologias do discurso jurídico) resta que, na tradução juramentada, a situação de produção do texto traduzido é de natureza jurídica (fé pública). Esta constatação reforça a hipótese de que, na tradução juramentada, nos deparamos com uma situação potencialmente conflitante, em que a tipologia textual tenderia a demandar a busca intensa de equivalências lingüístico-culturais correntes na língua/cultura alvo, enquanto que a função comunicativa do ato tradutório buscaria privilegiar as soluções imitativas, de decalques formais e semânticos.

\footnotetext{
${ }^{2}$ Para um estudo que questiona a hipótese da maior literalidade na tradução juramentada, vide Stupiello, 2001 .
} 


\section{O MATERIAL DE ANÁLISE}

Responder a estas questões pode demandar um conjunto de investigações de certo vulto, sobre um corpus relativamente extenso (vide Aubert \& Tagnin, 2004). Aqui, um ensaio preliminar, exploratório, que, a despeito de suas limitações de escopo, permite registrar algumas características da prática profissional dos tradutores públicos na lide com esta aparente contradição. Para tanto, conduziu-se um levantamento junto a tradutores públicos habilitados no Estado de São Paulo para o idioma inglês, buscando averiguar de que modo lidam com construções lingüística ou culturalmente marcadas, em ambas as direções tradutórias. Foram propostos alguns fraseologismos do português brasileiro e outros fraseologismos do inglês norte-americano, todos com elevada recorrência em textos normalmente submetidos à tradução juramentada, solicitando-se aos tradutores que indicassem sua maneira preferencial de verter/traduzir esses fraseologismos. Doze tradutores cooperaram com o levantamento, em alguns casos encaminhando mais de uma sugestão tradutória.

A escolha de fraseologismos, e não de segmentos textuais mais 'neutros', foi deliberada. Em termos mais gerais, o fraseologismo contém, usualmente, fortes marcas culturais (lingüísticas, no sentido de "modo de dizer" e extra-lingüísticos, ou referenciais), e, portanto, no caso do dilema sugerido em nossa hipótese de partida, agudizariam a tensão entre demandas conflitantes, tornando, é de se esperar, mais visível a atuação dessas forças e, portanto, facultando uma análise mais apurada. Em termos mais específicos, ao menos para alguns desses fraseologismos da língua fonte, existem correspondentes em uso corrente na língua meta. Tal situação favoreceria, em tese, a substituição plena de um fraseologismo por outro, a equivalência/invariança estabelecendo-se no plano discursivo, funcional, não no plano intralingüístico (lexical e morfossintático). Assim, por exemplo, em um ato notarial, in witness/testimony whereof encontra seu equivalente discursivo e funcional, em português brasileiro, na expressão o referido é verdade e dou fé. No entanto, a ser correta a hipótese literalizante delineada acima, a expectativa seria encontrar, mesmo no co-texto notarial em questão, soluções como em testemunho do quê.

Dentre os fraseologismos propostos, o presente estudo focalizará:

em inglês:

(i) I, John R. Smith, notary public duly qualified in and for the County of New Castle ...

(ii) The Parties will exercise reasonable good faith efforts to resolve the dispute.

e, em português:

(i) O Reitor da Pontifícia Universidade Católica de São Paulo, no uso de suas atribuições

(ii) ..., brasileiro, casado, engenheiro civil, portador da cédula de identidade RG nn..nnn.nnnSSP-SE, e inscrito no CPF/MF sob . $^{\circ} \mathrm{xxx} . \mathrm{xxx} ; \mathrm{xxx}-\mathrm{xx}$, residente e domiciliado em ... 
AUBERT - Dilemas da literalidade na tradução juramentada

\section{NOTÁRIOS/TABELIÃES, CONDADOS/DISTRITOS/MUNICÍPIOS}

Para a tradução de um dos fragmentos mais simples da amostra, o ato performativo de reconhecimento de firma em inglês americano, foram apresentadas as seguintes contribuições:

1. Eu, John R. Smith, tabelião público devidamente qualificado em e para o Condado de New Castle....

2. Eu, John R. Smith, tabelião público devidamente habilitado no Distrito de New Castle

3. Eu John R Smith, notário público legalmente nomeado no e para o Distrito de New Castle

4. Eu, John R. Smith, tabelião devidamente habilitado no e pelo condado de New Castle ... 5. Eu, John R. Smith, notário público devidamente qualificado no e para o Condado de New Castle...

6. Eu, John R. Smith, tabelião público devidamente habilitado no Condado de New Castle e para o mesmo Condado...

7. Eu, John R. Smith, notário público devidamente habilitado a exercer meu ofício nos limites e em nome do Condado de New Castle, ...

8. Eu, John R. Smith, tabelião público devidamente qualificado pelo e para o Condado de New Castle...

9. Eu, John R. Smith, tabelião devidamente habilitado no Condado de New Castle para nele exercer suas funções

10. Eu, John R. Smith, tabelião devidamente comissionado [habilitado] no Condado de New Castle e para o Condado de New Castle...

11. Eu, John Smith, tabelião devidamente qualificado no Condado de New Castle para ali atuar ...

12. Eu, John R. Smith, tabelião público devidamente licenciado no Condado de New Castle...

13. Eu, John R. Smith, tabelião devidamente habilitado em New Castle e com jurisdição nesse município...

14. Eu, John R. Smith, tabelião devidamente habilitado por e perante o Condado de New Castle .......

Duas constatações se fazem logo de imediato: (1) todas as alternativas iniciam-se de forma idêntica, ou seja, com o discurso direto em primeira pessoa do singular- embora tecnicamente fosse possível recorrer à terceira pessoa do singular - consistente com a forma de certificação do próprio tradutor, em seu termo de abertura (Certifico e dou fé ...), também em primeira pessoa do singular; (2) a despeito do início compartilhado, e embora se trate de uma formulação bastante invariável no idioma de partida, na seqüência observamse, em 14 propostas, 14 formulações distintas.

A variação observada prende-se em parte a diferenciações de natureza referencial (marcadores culturais), em parte a diferenciações lingüísticas. As questões culturais dizem 
Trab.Ling.Aplic., Campinas, 44(2) - Jul./Dez. 2005

respeito, primordialmente, aos termos "notary" e "county", as lingüísticas a "duly", a "qualified", e à construção "in and for".

Simplificando a questão, pode-se dizer que o notary public americano e o tabelião público brasileiro exercem funções similares, mas de modo distinto, e com base em procedimentos de habilitação e de fiscalização de suas atividades também distintos; já entre o notary public britânico e o tabelião público brasileiro, o grau de semelhança é um pouco maior. Talvez por esse motivo, os consulados brasileiros localizados nos EUA, ao autenticarem a assinatura do notary public, designam-no como notário público (termo, aliás, que começa a se fazer corrente também no Brasil); já os consulados brasileiros no Reino Unido tendem a referir-se a esses oficiais como tabeliães. Por outro lado, para os efeitos da autenticação, o notary public que se faz presente, por ato notarial, em um instrumento qualquer expedido nos EUA, exerce uma função que, no Brasil, seria exercida por um tabelião.

Em outros termos: se, do ponto de vista institucional na cultura de origem, o notaryé apenas similar mas não idêntico ao tabelião (consideração que justificaria a opção por uma forma marcada, isto é, menos usual em português, ou seja, notário), no uso específico institui-se uma sinonímia funcional e situacional entre o notary e o tabelião (o que, por sua vez, justificaria a opção por uma forma não marcada na língua de chegada, ou seja, tabelião). Na opção por notário, sublinha-se a alteridade cultural. Na opção por tabelião, enfatiza-se a similaridade funcional, e evita-se o efeito de estranhamento cultural, talvez desnecessário para os fins da tradução juramentada neste ponto (reconhecimento de firma, e atos similares). Essa foi a opção da maioria $(78,5 \%)$ dos contribuintes à amostragem. Ressalve-se, porém, que a tradução de notary public por tabelião público poderá gerar incongruência interna seja internamente, no texto traduzido, seja no confronto entre a tradução e o original - se, além do ato notarial original, o documento contiver uma consularização, caso em que, como já ficou dito, o consulado brasileiro utilizará, em português, o termo notário.

Na tradução de county, embora se possa entrever um certo paralelismo com a relação notary/tabelião, o comportamento foi diametralmente oposto: apenas $21,5 \%$ das traduções propostas optaram por uma busca da similaridade funcional (distrito, município), os demais retendo a opção já consagrada de preservação da alteridade cultural, com o termo condado. Ficou ausente da amostra uma opção mais estreitamente vinculada ao Poder Judiciário, relevante para a possível intersecção cultural, ou seja, comarca.

À primeira vista, teríamos, aqui, um comportamento revelador de uma certa inconsistência na postura tradutória. No entanto, é possível atribuir a aparente discrepância a um esforço deliberado, ainda que não necessariamente refletido. Nos 64,3\% dos casos em que co-ocorrem as soluções tabelião e condado, é possível perceber, por parte dos tradutores, uma busca de equilíbrio entre a dizibilidade natural em português e a recuperação da especificidade cultural do texto em língua inglesa, entre a construção de um texto de boa legibilidade e o "alerta" ao leitor da tradução de que deve interpretar o texto não na óptica de sua própria cultura, e sim na da cultura que originariamente gerou o texto de partida. 
AUBERT - Dilemas da literalidade na tradução juramentada

Em apenas uma das propostas, o termo duly aparece traduzido como legalmente (em todas as demais, os tradutores optam pela forma consagrada, devidamente). Trata-se, tanto quanto se pode apreender, de uma tentativa de evitar uma fórmula padrão, marcadora deste tipo de segmento textual, e atribuir ao trecho em que se insere uma marca mais vernacular na língua de chegada. Esta mesma proposta contém a opção notário para notary e distrito para county, o que reforça a reflexão sugerida no parágrafo precedente: a busca do equilibro entre as duas culturas e as duas "formas de dizer".

Para o termo qualified, a amostra sugere as seguintes alternativas: qualificado, habilitado, nomeado, comissionado e licenciado. No uso vernacular, qualificado é apenas um parente etimológico de qualified, mas não significa a mesma coisa; portanto, ao menos em tese, não constitui, apesar das aparências em contrário, uma 'tradução literal' estrita, nem mesmo no discurso jurídico (em que termos como qualificar e qualificação normalmente vêm associados à identificação das partes). No contexto do trecho em exame, porém, a solução qualificado acaba assumindo um sentido próximo ao do original, pela referência clara à área em que o notary/tabelião exerce o seu ofício; ou seja, o texto traduzido institui um novo sentido para o termo qualificado, apreensível como tal apenas no contexto em questão. Em todas as demais propostas (representando mais de $70 \%$ do total), a opção foi por um termo vernacular em português que traduzisse o sentido, não a forma, do original.

In and for - a coordenação preposicional - é uma construção relativamente comum em inglês, especialmente no discurso jurídico. Outros exemplos são by and between/among, ou, como locução prepositiva, in the name and on behalf of, construções essas essencialmente redundantes. Já em português, embora teoricamente possível, trata-se de uma construção percebida como não idiomática e, portanto, a ser evitada. No entanto, a despeito da redundância e da não idiomaticidade desta construção, percebe-se, na amostra, a tendência literalizante da tradução juramentada. Com efeito, sobre 14 contribuições, 6 (43\%) recriam em português a coordenação preposicional (em e para; no e pelo; pelo e para; por e perante), enquanto que outras 6 procuram amenizar a não idiomaticidade por meio de construções mais elaboradas, como em ... nos limites e em nome do ..., ou em N.C. e com jurisdição nesse .... Observa-se, aqui, a contrapartida morfossintática do mesmo procedimento adotado no plano semântico com a tradução qualified = qualificado: a instituição de uma forma admissível em português tão somente por tratar-se de uma situação tradutória (tecnicamente, um fenômeno de interlíngua); ou seja, quando utilizado na situação de tradução juramentada de texto original em língua inglesa, e em segmentos textuais percebidos como constituindo fórmulas fixas ("cristalizadas") em inglês, passa a ser tido por aceitável.

\section{ENVIDANDO, DE BOA FÉ, OS ESFORÇOS CABÍVEIS}

No fragmento The Parties will exercise reasonable good faith efforts to resolve the dispute, há quatro desafios tradutórios a considerar: (i) a questão fraseológica, localizada em exercise ... efforts; (ii) a questão terminológica, em good faith; (iii) o uso idiomaticamente 
marcado de reasonable como relativizador do valor absoluto da assertiva; e (iv) o relativo longo rol de parassinônimos, em inglês e em português, para o conceito expresso em dispute.

Os tradutores apresentaram as seguintes contribuições:

1. As Partes [ora contratantes] envidarão seus melhores esforços [empenhar-se-ão razoavelmente], de boa fé, para dirimir a presente dúvida/disputa.

2. As Partes buscarão utilizar esforços justos na solução da disputa.

3. As Partes empreenderão todos os esforços cabíveis de boa fé, para dirimir o pleito.

4. As Partes empreenderão, de boa fé, todos os esforços cabíveis para dirimir o pleito.

5. As Partes envidarão de boa fé esforços razoáveis para resolver a controvérsia.

6. As partes envidarão de boa fé os esforços possíveis para solucionar o litígio

7. As Partes envidarão esforços para solucionar a controvérsia, com moderação e boa-fé.

8. As Partes envidarão todos os esforços possíveis para resolver a questão.

9. As Partes envidarão, em medida razoável, esforços de boa-fé para resolver a disputa. 10. As Partes farão uso de razoáveis esforços de boa-fé para a solução da controvérsia. 11. As Partes imbuir-se-ão de esforços bem intencionados para resolver a disputa.

12. As Partes se empenharão, dentro do razoável e de boa fé, para resolver a pendência. 13. As partes, de boa fé, envidarão esforços para dirimir o litígio.

14. Para dirimir a controvérsia, as partes comprometem-se a envidar esforços em boa-fé, dentro de parâmetros razoáveis.

A variedade observada (14 contribuições e, novamente, 14 soluções ao menos parcialmente distintas entre si) aqui surpreende menos do que no caso analisado no item anterior. Naquela, tratava-se de uma construção formulaica padrão, para a qual existe construção formulaica equivalente igualmente padrão em português brasileiro. No presente caso, temos uma construção textual específica, que inclui, é bem verdade, um fraseologismo, mas que comporta, mesmo no idioma fonte, várias construções alternativas e igualmente idiomáticas, tais como:

1. The Parties will exercise reasonable efforts, in good faith, to resolve the dispute;

2. Under any such dispute, the Parties will exercise reasonable good faith efforts to arrive at a mutually satisfactory settlement;

3. The Parties hereby mutually agree to duly exercise all reasonable efforts, in good faith, to settle the dispute;

4. The Parties hereto will exercise reasonable good faith efforts to solve the dispute;

e assim por diante.

O fraseologismo exercise ... efforts tem como equivalente idiomático em português envidar ... esforços. Do total de sugestões apresentadas, 57\% consignam esta alternativa, ou seja, aproximam o texto traduzido da forma de expressão correspondente aos 'usos e costumes' da língua alvo. Outros $14 \%$ sugerem a construção empreender esforços, que, sem constituir um fraseologismo tão marcado quanto envidar esforços, constitui uma 
AUBERT - Dilemas da literalidade na tradução juramentada

combinatória bastante encontradiça (uma "coligação") em português. Na busca pelo estabelecimento de uma equivalência estritamente semântica, 22\% das propostas trazem alternativas tais como buscar utilizar, fazer uso ou, ainda, fundindo em uma única forma verbal - empenhar-se - os dois termos do fraseologismo. Nestas alternativas tradutórias, não há a recuperação do efeito fraseológico. Apenas uma das propostas apresenta um desvio que resulta em uma impropriedade semântica (imbuir-se de esforços). Em síntese, com ou sem o recurso a fraseologismos da língua alvo, o esforço de tradução resultou, neste ponto, em soluções naturais para o português brasileiro, preservando a literalidade semântica, mas sem gerar seqüências divergentes dos usos da língua de tradução.

O termo good faith tem seu equivalente literal em português brasileiro de uso consagrado (inclusive na legislação): boa fé (com uma variante ortográfica boa-fé). Esta é uma situação particularmente favorável para a manutenção da literalidade e do paralelismo intertextual original/tradução, sem gerar percepção de desvio na língua alvo (interlíngua). Assim, era de se esperar que todas as propostas adotassem boa fé como equivalente de tradução de good faith. No entanto, ocorreram soluções divergentes, tais como justos, bem intencionados, além de uma omissão (vide alternativa 8.). Considerado o termo em isolamento, não haveria motivo aparente para tais desvios. Visto como parte constituinte de toda a oração, porém, é possível que a busca de soluções divergentes tenha sido um efeito direto da percepção de que a boa fé, no universo jurídico brasileiro, é absoluta e implícita (em todo ato jurídico, há presunção de boa fé), e, portanto, que sua expressão na oração é, no mínimo, redundante, e um efeito colateral da real dificuldade imposta pelo qualificador reasonable. Nesse sentido, a omissão (como forma de evitar a redundância), pode parecer justificável.

Tal como empregado em textos jurídicos em língua inglesa (particularmente, estadunidenses), o termo reasonable tem por função instituir uma ressalva, uma limitação ao que de outro modo constituiria uma declaração ou um compromisso absoluto. Introduz, portanto, um elemento de moderação, de espaço para a subjetividade e para a falibilidade humana, um pouco no mesmo sentido de to the best of my knowledge and ability, ou and I verily do believe [something] to be a true and correct ... . Esta já é uma limitação que diverge da concepção jurídica inspirada no Direito Romano e na tradição positivista: assim, em um processo de autenticação, por exemplo, ou se declara a assinatura como autêntica, sem restrições, ou não se executa a autenticação. É estranho à nossa prática de atos jurídicos proceder a um ato notarial de autenticação com uma ressalva do tipo tanto quanto é de meu conhecimento, ou similar.

No mesmo sentido, a boa-fé, no conceito brasileiro, constitui um valor absoluto, não passível de qualificação. Uma ação se conduz de boa ou de má fé, não há como conceber um plano intermediário, de uma "boa-fé com ressalvas". Ora, na estrutura original reasonable good faith efforts - o termo em discussão pode aplicar-se tanto a efforts (esforços) quanto a good faith (boa-fé), constituindo, portanto, uma construção sintática e semanticamente ambígua. Em português, um esforço pode ser cabível (é possível graduar o esforço, em diversos níveis de empenho); a boa-fé não (ou se tem ou não se tem boa fé); e, portanto, a tradução terá necessariamente de desfazer a ambigüidade do original. 
Percebe-se claramente os efeitos desta dificuldade na grande variação de soluções tradutórias propostas, por vezes algo forçadas:

1.... seus melhores esforços [empenhar-se-ão razoavelmente], de boa fé

2. ... esforços justos

3. ... todos os esforços cabíveis de boa fé

4. ... de boa fé, todos os esforços

5. ... de boa fé esforços razoáveis

6. ... de boa fé os esforços possíveis

7. ... esforços ..., com moderação e boa-fé

8. ... todos os esforços possíveis

9. ... em medida razoável, esforços de boa-fé ...

10. ... razoáveis esforços de boa-fé ...

11. ... esforços bem intencionados ...

12. ... dentro do razoável e de boa fé, ...

13. ... de boa fé, ... esforços ...

14. ... esforços em boa-fé, dentro de parâmetros razoáveis,

que abrangem desde omissões (estratégia de evitação), passando por fusões entre os conceitos de reasonable e good faith (possíveis, justos), adverbializações ligadas diretamente ao verbo (empenhar-se-ão razoavelmente), o adjetivo razoável em diversas formas de inserção, a solução algo curiosa (e com desvio de sentido) com moderação, até o termo mais formal (e, nessa perspectiva, mais apropriado à linguagem jurídica), cabível.

$\mathrm{O}$ trecho final do fragmento - to resolve the dispute - oferece à observação uma questão estritamente lingüística. Aqui temos também um fraseologismo, menos cristalizado, porém, do que reasonable good faith efforts -, posto que resolve poderia ser substituído por settle. Em português brasileiro, há um certo número de fraseologias equivalentes, em especial dirimir/solucionar a questão/contendalcontrovérsia, eventualmente pendência. Pleito e dúvida não configuram uma matéria controversa, que é o sentido de dispute (seja como nome ou como verbo), enquanto litígio, embora estritamente falando correto, por efeito da interlíngua da tradução inglês à português poderia ser facilmente assimilado a litigation, situação em que a controvérsia já saiu da esfera do entendimento extrajudicial, para ganhar os tribunais (do Judiciário ou das Câmaras de Arbitragem), gerando, portanto, risco de obscurecimento do efeito pretendido pelo dispositivo em questão (evitar, tanto quanto possível, o recurso a instâncias externas às próprias partes ao contrato).

Tal como no primeiro fragmento discutido acima, observa-se também aqui (i) uma certa tensão entre a busca da idiomaticidade lingüística (envidar esforços) e a manutenção da alteridade cultural e lingüística (esforços de boa fé); (ii) a geração de soluções de forma e/ou de sentido aceitáveis apenas por tratar-se de texto explicitamente traduzido (interlíngua). Finalmente, é forçoso que se diga, (iii) uma incidência algo maior de soluções tradutórias menos convincentes, aparentemente reveladoras de uma combinação da efetiva dificuldade do trecho em questão, em que se sobrepõem às questões idiomáticas concepções 
AUBERT - Dilemas da literalidade na tradução juramentada

jurídicas distintas, com a evidente busca de um literalismo semântico exigido ou percebido como sendo exigido pela natureza da tradução juramentada.

\section{DE REITOR A PRESIDENT}

O fragmento típico de diploma emitido por instituição de nível superior - O Reitor da Pontifícia Universidade Católica de São Paulo, no uso de suas atribuições ... - gerou 13 propostas distintas, a saber:

1. The Rector of the university Pontifícia Universidade Católica de São Paulo, in use of his powers

2. The President of the Pontifícia Universidade Católica de São Paulo [Pontifical Catholic University of São Paulo] pursuant to his attributions

3. The President of the Pontifícia Universidade Católica de São Paulo, by the authority of the law...

4. The Dean of the Pontifical Catholic University, by virtue of the authority vested in the Board of Governors ...

5. The President of the Pontifical Catholic University, in the use of his prerogatives ...

6. The President of the Pontifical Catholic University of São Paulo, in the capacity conferred upon him...

7. The Rector of the "Pontifícia Universidade Católica de São Paulo" (Pontific Catholic University of São Paulo), by virtue of the authority vested in him

8. The President of the Pontifical Catholic University of São Paulo, exercising the prerogatives granted to him...

9. The dean of the São Paulo's Catholic University, in the use of the authority vested in him

10. The President of Pontifícia Universidade Católica de São Paulo, with the authority vested in him...

11. The Rector of Pontifícia Universidade Católica de São Paulo, in the use of his legal attributions...

12. The Rector of 'Pontifícia Universidade Católica de São Paulo, in the powers vested in him...

13. I, the Rector of the Pontifical Catholic University of São Paulo, by virtue of the authority vested in me

Aqui, são três os pontos chave para a perspectiva de análise aqui adotada: (i) a designação do cargo; (ii) o nome da instituição; e (iii) o fraseologismo no uso de suas atribuições, empregado no contexto específico (diploma emitido por instituição de ensino superior brasileira). Os dois primeiros colocam questões lingüísticas e referenciais; o terceiro é fundamentalmente uma questão de "modo de dizer".

As 13 alternativas oferecem 3 soluções para designar o cargo: President (46,1\%), Rector $(38,5 \%)$ e Dean $(15,4 \%)$. A primeira estabelece equivalência com a realidade 
Trab.Ling.Aplic., Campinas, 44(2) - Jul./Dez. 2005

institucional da língua/cultura alvo; a segunda, transporta a terminologia da língua/cultura fonte para o texto traduzido (solução literalizante), apoiado no fato de que Rector pode de fato ser empregado para designar o supremo mandatário de uma universidade, seminário e faculdade, em especial quando se trata (como no caso presente), de uma instituição confessional. Assim, embora menos usual do que President, há uma intersecção possível entre Reitor e Rector que justifica a solução e possibilita, concomitantemente, a manutenção de uma formulação típica da língua/cultura/texto de partida com uma razoável transparência na língua/cultura alvo. Dean, teoricamente, constitui um erro, pois normalmente designa o diretor acadêmico (por oposição ao diretor administrativo) de uma faculdade ou instituto, em um nível hierárquico abaixo do da Universidade.

Para o nome da instituição, observa-se uma variação entre a manutenção da forma original, em português brasileiro uma tradução literal - Pontifical Catholic University (of São Paulo) - (ambas com frequiência de 38,5\%) e o uso de ambas as formas - português e inglês - $(15,4 \%)$. Apenas uma das soluções propostas rompe com o literalismo mais estreito (empréstimo ou transposição), mas resulta em uma solução pouco idiomática em inglês: São Paulo's Catholic University (uma solução mais adequada teria sido Catholic University of São Paulo).

A expressão no uso de suas atribuições tem como equivalente discursivo em inglês americano o fraseologismo by virtue of the powers vested in me. Como tal, pressupõe uma manifestação em primeira pessoa do singular (algo como "I, John Doe, President of ..."), enquanto que o original em português se expressa em terceira pessoa do singular. Para adequar o texto traduzido aos "usos e costumes" da língua de chegada, portanto, o fragmento todo teria de ser reescrito na primeira pessoa. Apenas uma das propostas (vide alternativa 13) avançou a este ponto. Os demais mantiveram a forma impessoal, com o quê a tradução deste dispersa-se por diversas tentativas, algumas algo claudicantes, com perda do efeito de idiomaticidade inerente ao fraseologismo. Note-se que, para este trecho, as 13 propostas oferecem 13 soluções ao menos em parte distintas, o que sugere, neste ponto, uma discrepância idiomática relativamente forte entre os dois complexos língua/cultura em confronto.

\section{QUALIFICAÇÃO DA PARTE}

Contratos, procurações e instrumentos similares contêm, entre outros elementos previsíveis, a nomeação e a qualificação das partes. Por qualificação das partes entendese, normalmente, dados suplementares ao nome (pessoa física) ou à razão social (pessoa jurídica) que contribuam para identificar a parte em questão. Em algumas tradições jurídicoinstitucionais, basta o número de identidade ou a data de nascimento para a pessoa física, ou o número de inscrição no registro societário no caso da pessoa jurídica. Em outras, notadamente a brasileira, a praxe é a de fornecer um número elevado de dados suplementares, até mesmo o estado civil da pessoa, ainda que tal informação não seja diretamente relevante para os propósitos do instrumento em questão. 
AUBERT - Dilemas da literalidade na tradução juramentada

Assim, o fragmento “... brasileiro, casado, engenheiro civil, portador da cédula de identidade RG nn..nnn.nnn-SSP-SE, e inscrito no CPF/MF sob n. ${ }^{\circ} x x x . x x x ; x x x-x x$, residente e domiciliado em ..." é, por sua própria estrutura interna, discrepante em relação aos usos anglo-americanos, para os quais o cargo que ocupa ou, eventualmente, o $\mathrm{n}^{\mathrm{o}}$ do passaporte constituiriam suplementos informativos suficientes para sua caracterização. Em uma tal situação, portanto, qualquer que seja a solução tradutória dada, esta tenderá a ser marcadamente estrangeirizadora, percebida na tradução como uma forma não habitual de expressão.

No material coligido, foram ofertadas dez alternativas de tradução:

1. Brazilian, married, civil engineer, bearer of the Id. Card RG nn......nn.......nn and enrolled with the Individual Taxpayer Registration under CPF/MF ${ }^{\circ} \mathrm{xxx} . \mathrm{xxx} . \mathrm{xxx}-\mathrm{xx}$, resident and domiciled in

2. Brazilian, married, civil engineer, holder of the Identity Card RG nn.nnn.nnn-SSP-SE, and registered in the Brazilian Tax Contributors Register CPF/MF under Number $\mathrm{xxx} . \mathrm{xxx} . \mathrm{xxx}-\mathrm{xx}$, resident and domiciled in ...

3. Brazilian, married, a Civil Engineer, bearer of the ID Card-RG nn.nnn.-SSP-SE, enrolled with the Brazilian Tax Authority CPF/MF under n. xxxxxxxxxxxxx, resident and domiciled in/at

4. Brazilian, married, civil engineer, bearer of identification card XXXX and enrolled in the individual taxpayer roll under number ...., resident and domiciled in ..., a Brazilian citizen, married, civil engineer, ID Card No. nn.nnn.nnn-SSP-SE, enrolled with the Individual Taxpayers' Registry under No. Xxx.Xxx.Xxx-Xx, residing and domiciled at

5. ..., Brazilian citizen, married, civil engineer, bearer of Identity Card ["RG"] no. nn.nnn.nnn-nn issued by the Secretariat of Public Security of the State of Sergipe ["SSPSE"], and enrolled with the Individual Taxpayer Registry issued by the Ministry of Finance [“CPF/MF”] under no. xxx.xxx.xxx-Xx, resident and domiciled in...

6. ..., Brazilian, married, civil engineer, bearer of Identity Card $N^{o}$ nn.nnn.nnn, issued by the Secretariat of Public Security of the State of Sergipe, and enrolled with Individual Taxpayers Register (of the Finance Ministry) under $N^{o} x x x . x x x . x x x-x x$, residing and domiciled at... / in...

7. Brazilian, married, Civil Engineer, holder of national identity card, RG nn.nnn.nnn issued by the Secretariat for Public Security of the State of Sergipe, and in the Ministry of Finance Individual Taxpayers Register - CPF xxx.xxx.Xxx-Xx, resident and domiciled in 8. Brazilian, married, civil engineer, bearer of Identity Card RG number nn..nnn.nnn-SSPSE and enrolled in the Taxpayers' National Registry under CPF/MF number xxx.xxx; xxx$\mathrm{xx}$, residing at

9. Brazilian, married, civil engineer, bearer of identity document RG No. nn.nnn.nnn-SSP$\mathrm{SE}$, and CPF/MF under N. ${ }^{\circ} \mathrm{xxx} . \mathrm{xxx} ; \mathrm{xxx}-\mathrm{xx}$, residing and domiciled in/at

10. Brazilian citizen, married, civil engineer, bearer of identification card No. nn,nnn,nnn$\mathrm{SSE} / \mathrm{SE}$, registered with the Finance Ministry as individual taxpayer No. xxx, $\mathrm{xxx}, \mathrm{xxx}-\mathrm{xx}$, resident and domiciled in/at... 
Trab.Ling.Aplic., Campinas, 44(2) - Jul./Dez. 2005

A despeito do assinalado acima, este fragmento não apresenta grandes variações. A discrepância é, fundamentalmente, discursiva, textual, não frástica ou sub-frástica, nem sequer lexical. Assim, registra-se uma elevada unanimidade nas soluções dadas para o trecho inicial - brasileiro, casado, engenheiro civil - apenas com alguma variação entre Brazilian e sua explicitação Brazilian citizen (20\%). Para o termo portador, as traduções oscilam entre bearer e holder, ambos idiomáticos na língua alvo e aceitáveis no contexto em questão. A grande variação que se observa nas formulações propostas para lidar com as especificidades da cultura fonte $S S P, R G$ e $C P F$ vem tratada, por uma questão de organização temática, no item subseqüente.

\section{OS MARCADORES CULTURAIS E A DISPERSÃo NAS SOLUÇÕES TRADUTÓRIAS}

Os principais marcadores culturais utilizados na amostragem são: (a) na direção tradutória inglês à português: notary public e county; (b) na direção tradutória português à inglês: reitor, Pontifícia Universidade Católica, SSP-SE, CPF e RG.

No caso dos marcadores culturais, a hipótese preliminar - atestada em vários outros estudos desta natureza (mas voltados sobretudo para a tradução literária) - sugere que a tendência tradutória nesses casos será optar pelos extremos da escala tradutória: de um lado, o empréstimo, de outro a adaptação, isto é, entre uma reprodução do termo original (eventualmente destacado em itálico ou entre aspas, ou 'disfarçado' como um decalque) e sua substituição por um termo parcialmente equivalente, próprio da língua-meta, em ambos os casos com o eventual acréscimo de uma explicação (sob forma de um aposto, uma observação parentética ou, no limite, uma nota de rodapé). Já se observou, acima, esse tipo de tendência no tratamento de notary public (traduzido ora por notário, ora por tabelião) e de county (traduzido mais freqüentemente por condado - decalque - ou por municípiol distrito - adaptação).

Considerando, em conjunto, as opções adotadas pelos tradutores participantes da amostragem para todos os marcadores culturais, observamos a seguinte distribuição: 


\begin{tabular}{|c|c|c|}
\hline \multirow{3}{*}{$\begin{array}{l}\text { Notary } \\
\text { Public }\end{array}$} & tabelião & 5 \\
\hline & tabelião público & 5 \\
\hline & 3. notário público & 3 \\
\hline \multirow{3}{*}{ County } & 1. Condado & 10 \\
\hline & 2. Distrito & 2 \\
\hline & 3. Município & 1 \\
\hline \multirow{3}{*}{ Reitor } & 1. President & 6 \\
\hline & 2. Rector & 5 \\
\hline & 3. Dean & 2 \\
\hline \multirow{4}{*}{$\begin{array}{l}S S P \text { - } \\
S E\end{array}$} & 1. SSP-SE & 6 \\
\hline & $\begin{array}{l}\text { 2. issued by the Secretariat of Public Security of the State of } \\
\text { Sergipe }\end{array}$ & 2 \\
\hline & $\begin{array}{l}\text { 3. issued by the Secretariat of Public Security of the State of } \\
\text { Sergipe ["SSP-SE"] }\end{array}$ & 1 \\
\hline & 4. omissão & 1 \\
\hline \multirow{5}{*}{$P U C$} & 1. Pontifical Catholic University & 6 \\
\hline & 2. Pontifícia Universidade Católica & 3 \\
\hline & $\begin{array}{l}\text { 3. Pontifícia Universidade Católica (Pontifical Catholic } \\
\text { University) }\end{array}$ & 2 \\
\hline & 4. university Pontifícia Universidade Católica & 1 \\
\hline & 5. Catholic University & 1 \\
\hline \multirow{8}{*}{ CPF } & 1. Individual Taxpayer Registry & 2 \\
\hline & 2. Individual Taxpayers Register & 2 \\
\hline & 3. Individual Taxpayer Registration under CPF/MF & 1 \\
\hline & 4. Brazilian tax Contributors Register CPF/MF & 1 \\
\hline & 5. Individual Taxpayer Roll & 1 \\
\hline & 6. Taxpayers National Registry & 1 \\
\hline & 7. $\mathrm{CPF}$ & 1 \\
\hline & 8. Individual Taxpayer & 1 \\
\hline \multirow{8}{*}{$R \boldsymbol{G}$} & 1. ID Card No. & 2 \\
\hline & 2. Identity Card RG & 2 \\
\hline & 3. ID Card-RG & 1 \\
\hline & 4. Id. Card RG & 1 \\
\hline & 5. IDENTIFICATION CARD & 1 \\
\hline & 6. identification card No. & 1 \\
\hline & 7. Identity Card & 1 \\
\hline & 8. Identity Card ["RG'] & 1 \\
\hline
\end{tabular}


Trab.Ling.Aplic., Campinas, 44(2) - Jul./Dez. 2005

O que mais chama a atenção nesse levantamento é a diferença no grau de dispersão. Em alguns casos, sobre 13 contribuições, as opções limitam-se a no máximo 3, com concentração em 2 delas; em alguns outros, as opções se espalham entre até 8 alternativas ao menos parcialmente distintas.

Uma primeira hipótese explicativa poderia ser a direção tradutória. Bem ou mal, há uma tradição mais consolidada na expressão da realidade cultural anglo-americana no português do que no sentido inverso. Poder-se-ia argumentar, até certo ponto com razão, que na situação contemporânea, a cultura anglo-americana exerce um papel universalizante, e assegura mais facilmente sua dizibilidade em outras culturas, enquanto que essas, sendo mais "exóticas" em relação à cultura tida por dominante, se afigurariam, por isso mesmo, menos facilmente "dizíveis".

No entanto, o exemplo de Reitor acima, que apresenta uma distribuição e uma dispersão similar ao termo notary public indica que uma explicação fundamentada no conceito de correlação de forças culturais (e que sempre dá margem a apreciações subjetivas) não é suficiente e talvez nem mesmo constitua a linha explicativa principal. Mais relevante parece ser a própria natureza do marcador cultural, no sentido de sua maior ou menor especificidade.

Com efeito, notary public, county e Reitor remetem a realidades institucionais parcialmente distintas nas respectivas culturas, mas para as quais existem equivalentes: no Brasil como nos EUA, existem divisões geopolíticas administrativas locais, vinculadas aos poderes Executivo e Judiciário, ainda que sua configuração precisa não seja a mesma; no Brasil como nos EUA, existem pessoas investidas formalmente de fé pública, que reconhecem e autenticam documentos, cópias reprográficas, assinaturas, escrituras e outros instrumentos, ainda, que, novamente, com relações de investidura, escopo de atuação e inserção em escalas hierárquicas distintas; e, finalmente, existe, em ambas as culturas, a previsão do posto ou função de supremo mandatário de uma instituição universitária.

Universidades confessionais, inclusive universidades que se denominam católicas, também existem em ambas as culturas. O elemento divisor, que introduz uma dificuldade maior, está na designação "Pontifícia", ou seja, a indicação explícita no nome da instituição de que a universidade em questão foi credenciada/aprovada/reconhecida pela Santa Sé, comum no Brasil (em que nem todas as universidades católicas são Pontifícias) mas inusitada nos EUA. Assim, parece ser este o motivo principal para uma dispersão entre um número maior de alternativas na tradução para o inglês do conceito de Pontifícia Universidade Católica.

O caso da sigla $S S P-S E$, como órgão expedidor de cédula de identidade, parece situarse em uma zona intermediária. O conceito de uma Secretaria de Segurança (ou de Polícia, ou de Ordem Pública) é conhecida na administração anglo-americana tanto quanto na brasileira. A dificuldade está no termo Secretaria pois o termo preferencial nesse nível da hierarquia do poder executivo é Department. A tradução como Secretariat ou, mesmo, a manutenção da sigla sem maiores explicações, em lugar de Department of Public Security representa uma clara intenção literalizante.

Os casos mais evidentes são representados pelas siglas $R G$ e $C P F$. O próprio conceito de uma carteira de identidade é algo aversivo à cultura anglo-americana, que entende - 
AUBERT - Dilemas da literalidade na tradução juramentada

correta ou incorretamente, pouco importa - que a instituição de uma cédula de identidade só se justifica em situações de emergência nacional (como ocorreu, por exemplo, na II Guerra Mundial), mas que, em princípio, fere a liberdade individual. Já no caso do $C P F$ (ou CIC), que, para todos os efeitos, constitui um segundo documento de identidade no Brasil (o $R G$ é estadual, o $C P F$ é nacional), a similaridade com o número de inscrição na Social Security é por demais tênue para que se possa legitimamente substituir um pelo outro. $R G$ e $C P F$ configuram-se, pois, como marcadores culturais fortes, notary public, county e Reitor como marcadores culturais fracos, e PUC como marcador cultural intermediário. Pode-se, assim, sugerir que quanto mais específico (forte) o marcador, maior a variedade e a flutuação nas soluções tradutórias, a despeito de seu uso freqüente em originais e traduções, juramentadas ou não, que, ao longo dos anos, poderia ter consagrado uma determinada solução "de consenso", como no caso de sócio-quotista à quotaholder.

\section{À GUISA DE CONCLUSÃO}

Pelo que pretende ser - um texto traduzido caracterizado por sua invariância semântica e discursiva em relação ao texto original, um texto que se assume como tradução e, nesse sentido, como complemento e não como substituto do original - a tradução juramentada tenderia, a priori, a soluções marcadas por um maior grau de literalismo formal e semântico, e por uma explicitação maior das diferenças culturais extralingüísticas. Deveria, em suma, realizar, a seu modo, o ideal estrangeirizador de Venuti (op. cit.). Pelo que são os textos comumente submetidos à tradução juramentada, portadores de fortes marcas culturais lingüísticas e extralingüísticas, exigiriam, em seu traduzir, todo um trabalho de re-escrita e re-adequação cultural para evitar ou, ao menos, mitigar sua potencial opacidade na comunidade de recepção.

$\mathrm{Na}$ amostra aqui examinada, limitada alguns aspectos mais salientes de quatro estruturas fraseológicas contendo alguns marcadores culturais lingüísticos e extralingüísticos, pôde-se observar uma busca aparentemente deliberada (ou, em outro modo de ver, uma hesitação verbalizada) entre a dizibilidade natural na língua alvo e a recuperação da especificidade cultural do texto em língua fonte, entre a construção de um texto de boa legibilidade e o "alerta" ao leitor da tradução de que deve interpretar o texto não na óptica de sua própria cultura, e sim na da cultura que originariamente gerou o texto de partida. Esta busca se expressa de maneiras variadas, dentre as quais destacam-se:

(i) um elevado uso de soluções literalizantes, isoladamente ou em combinação com perífrases explicativas: condado por county, Rector por Reitor, ID Card RG, etc.

(ii) o uso, ao interior de um mesmo conjunto sintagmático, de soluções literalizantes e assimilativas, como em "tabelião de e para o condado de ...";

(iii) diversas opções de interlíngua, que instituem soluções tradutórias admissíveis justamente por tratar-se de tradução juramentada, como em qualificado por qualified ou todos os esforços cabíveis de boa fé como tradução de reasonable good faith efforts; 
(iv) a evidenciar o elevado grau de dificuldade na conciliação entre as demandas conflitantes, um índice relativamente elevado de inadequações (quer em termos semânticos, quer em termos estilísticos), como se evidencia nas opções por vezes algo tortuosas para a tradução do referido fragmento reasonable good faith efforts, como em:

- ... envidarão esforços ... com moderação e boa-fé ...

- ... razoáveis esforços de boa-fé ...

- ... envidar esforços de boa-fé, dentro de parâmetros razoáveis.

Finalmente, cabe assinalar (v) a flutuação no grau de dispersão das soluções tradutórias para os termos designativos de realidades institucionais específicas de cada língua fonte, sugerindo uma certa correlação (que não há de ser absoluta, mas pode caracterizar-se como tendência) entre o maior ou menor grau de especificidade (singularidade) cultural e uma maior ou menor dispersão nas soluções propostas, paralela, aparentemente, à flutuação no grau de dispersão das soluções propostas para os "modos de dizer" (marcadores de cultura lingüística, no sentido de Nida (1945)), como evidenciado pelo tratamento dado ao qualificador reasonable ou nas múltiplas tentativas de tradução para o inglês do fraseologismo no uso de suas atribuições.

\section{REFERÊNCIAS BIBLIOGRÁFICAS}

AUBERT, F. H. (2004a). Dúvidas e controvérsias: Discutindo a literalidade da tradução juramentada (1): notários/ tabeliães, condados/distritos/municípios. In Ipsis Litteris, Ano III, n. ${ }^{\circ} 12$. São Paulo: ATPIESP, março de 2004. p 5-6.

. (2004b). Dúvidas e controvérsias: Discutindo a literalidade da tradução juramentada (2): envidando, de boa fé, os esforços cabíveis. In Ipsis Litteris, Ano III, n. ${ }^{\circ} 13$. São Paulo: ATPIESP, junho de 2004. p 7-8.

. (2004c). Dúvidas e controvérsias: Discutindo a literalidade da tradução juramentada (3): os marcadores culturais e a dispersão nas soluções tradutórias. In Ipsis Litteris, Ano IV, n. ${ }^{\circ}$ 14. São Paulo: ATPIESP, setembro de 2004. p 7-8.

AUBERT, F. H. \& TAGNIN, S. E. O. (2004). Um corpus de traduções juramentadas - material de pesquisa lingüística, sociológica e histórica. In TradTerm 10. São Paulo: CITRAT/FFLCH/USP. p. 163-178.

NEWMARK, P. (1981). Approaches to translation. Oxford: Pergamon.

NIDA, E. (1945) Linguistics and ethnology in translation problems. In Word II.

STUPIELLO, E. N. de A. (2001). Implicações teóricas para a tradução do discurso legal. Dissertação de Mestrado. São José do Rio Preto: IBILCE/UNESP.

VENUTI, L. (1995). The translator's invisibility. Londres: Routledge. (2002). Escândalos da tradução: por uma ética da diferença. Bauru: EDUSC.

VINAY, J. P. e DARBELNET, J. (1958/1977) Stylistique comparée du français et de l'anglais. Paris: Didier.

ZANOTTO, P. (1993) Tipos de texto e modalidades de tradução. Tese de doutorado. São Paulo, USP. 